\title{
Just ask: discussing goals of care with patients in hospital with serious illness
}

\author{
John J. You MD MSc, Robert A. Fowler MD MS, Daren K. Heyland MD MSc; on behalf of the Canadian \\ Researchers at the End of Life Network (CARENET)
}

$\mathrm{O}$ ur population is aging, and older patients are living longer with chronic illness. Technology-laden end-of-life care is associated with poorer quality of life, lower satisfaction with care and increased anxiety and depression for family members. ${ }^{1}$ Advance care planning can increase the quality of life of dying patients, improve the experience of family members and decrease health care costs. ${ }^{1-3}$

Advance care planning is a process by which patients consider options for future health care decisions and identify their wishes. These decisions and wishes can vary depending on the setting. For example, during an acute stay in hospital, the plan may pertain to the goals of care for the current stay in addition to any care that may be required after discharge. In other settings, the plan may result in an advance care directive - a verbal or written instruction describing what kind of care a patient would want (or not want) if he or she were no longer able to speak for him or herself, and the values that guide the patient in making important health care decisions. Advance care planning may also result in the nomination of a substitute decision-maker - someone who makes decisions for the patient if the patient is incapable of doing so.

Patients in hospital with serious illness and their family members have identified improvements in end-of-life communication and decision-making as high-priority targets for quality improvement; ${ }^{4,5}$ however, hospital-based health care providers infrequently engage patients and families in such conversations. ${ }^{6}$ Accordingly, the focus of our review is to provide guidance for advance care planning as it pertains to the inpatient setting (i.e., determination of goals of care for the patient in hospital). Although health care providers in the outpatient setting (e.g., family physicians, consultant physicians) play a key role in advance care planning, hospital-based providers share this responsibility. In fact, a stay in hospital presents an important opportunity for engaging in discussions about goals of care, because it signals a change in the trajectory of the patient's illness, giving increased relevance to these conversations, and because potential substitute decision-makers (e.g., the most involved family members) are often present.

To organize our review, we use a communication and decision-making framework consisting of the following components: identifying patients at high risk of dying who need to have a discussion about goals of care; information exchange (regarding prognosis, values, and the risks and expected outcomes of various treatment options); and reaching a decision through discussion and deliberation. ${ }^{7}$ By providing structured guidance, specific advice and practical tools, our aim is to increase clinicians' confidence in engaging in meaningful end-of-life communication with patients in hospital and their family members. To inform this review, we drew on a broad range of evidence, from expert opinion to randomized controlled trials and systematic reviews (Box 1).

\section{Identifying patients at high risk of dying}

\section{How are patients who need to discuss goals of care identified?}

Although advance care planning is relevant for everyone, determining goals of care may not be pertinent for all patients in hospital (e.g., a healthy 32-year-old woman with pyelonephritis).
Competing interests: None declared.

This article has been peer reviewed.

Correspondence to:

John J. You,

jyou@mcmaster.ca

CMAJ 2014 DOI:10.1503 /cmaj.121274

\section{- Ker points}

- Clinicians can use the "surprise" question or more detailed clinical criteria to identify high-risk patients who need to determine their goals of care.

- When discussing goals of care with patients, clinicians should ask patients which family members they would like present and involve them in these conversations when possible.

- Key information to be exchanged during conversations about goals of care includes prognosis, the patient's values, and the risks and expected outcomes of life-sustaining treatments.

- Most patients who have an in-hospital cardiac arrest will not survive to discharge; of those who do survive, many will have substantially diminished function.

- Discussions about goals of care and any decisions made should be clearly documented in the patient's medical record. 
Given practical time constraints, the first step is to prioritize patients with whom a discussion needs to take place. The "surprise" question" ${ }^{8-11}$ ("Would I be surprised if this patient died in the next year?") is a suitable screening tool for this purpose (Box 2) ${ }^{6,11,12}$ If the answer to this question is "no," you should engage the patient in goals-of-care discussions and ask if there are any family members he or she would like to include. Because clinicians tend to overestimate their patients' life expectancies (at times by as much

\section{Box 1: Evidence used in this review}

We identified relevant evidence through targeted searches of MEDLINE (from inception to July 2012) using the following search terms: "advance care planning," "shared decision making" and "cardiopulmonary resuscitation." We supplemented the results of this search with material identified from our personal files and communication with experts in the field of end-of-life communication.

For the section dealing with clinical prediction rules, we identified original research articles describing the derivation or validation of a clinical prediction rule for all-cause mortality after hospital admission by searching for articles in any language in MEDLINE and Embase (from inception to July 2011) using the following search terms: "prognostic tool," "prognostic model," "prognostic index," "mortality" and "hospitalization." In addition, we searched our personal files and the reference lists of relevant articles and systematic reviews to identify any additional relevant articles.

We excluded studies that only involved patients with a specific disease (e.g., heart failure, chronic obstructive pulmonary disease), because patients admitted to hospital often have coexisting chronic conditions; studies examining the prognostic value of a single risk factor (e.g., anemia, hypoglycemia); studies restricted to the population of patients in intensive care units; and studies only reporting in-hospital mortality.

\section{Box 2: Identifying patients with a high risk of dying ${ }^{6,11,12}$}

These criteria can be used to identify patients with a high risk of dying. If a patient is determined to be at high risk, goals of care should be discussed with the patient and members of his or her family.

1. Age $\geq 55$ years and 1 or more of the following advanced chronic illnesses:

- Chronic obstructive pulmonary disease (2 of the following: baseline arterial partial pressure of carbon dioxide $>45 \mathrm{~mm} \mathrm{Hg}$, cor pulmonale, episode of respiratory failure within the preceding year, forced expiratory volume in $1 \mathrm{~s}<0.5 \mathrm{~L}$ )

- Congestive heart failure (New York Heart Association class IV symptoms and left ventricular ejection fraction $<25 \%$ )

- Cirrhosis (confirmed by imaging studies or documentation of esophageal varices) and 1 of the following: hepatic coma, Child class $C$ liver disease, Child class $B$ liver disease with gastrointestinal bleeding

- Cancer (metastatic cancer or stage IV lymphoma)

- End-stage dementia (inability to perform all activities of daily living, mutism or minimal verbal output secondary to dementia, bed-bound state prior to acute illness

Or

2. Any patient $\geq 80$ years of age admitted to hospital from the community because of an acute medical or surgical condition.

Or

3. You answer "no" to the following question: Would I be surprised if this patient died within the next year? as $430 \%),{ }^{13}$ we suggest supplementing the surprise question with objective clinical criteria (Box 2) $)^{6,11,12}$ that identify a population of patients with a high risk of dying. ${ }^{12}$

Having identified a patient in need of discussing goals of care, it may be informative to first contact the patient's family physician or consultant who manages the patient's predominant chronic illness to gain insight into any previous advance care planning that may have occurred. However, difficulties contacting outpatient physicians should not prevent starting the conversation directly with patients. In our experience, one way to start the conversation is with the following statements:

I am concerned about your overall health. Tell me how the past year has been going... Has anyone spoken to you in the past about what to expect from your disease and the kinds of treatments you would or would not want when you get really sick? ... Do you have a living will or advance directive, or know what these terms mean?

If the answer to the last question is "yes," the content of previous documents and discussions can be reviewed and updated if needed. If the answer is "no," further discussion is in order.

Although most patients with a serious illness and their family members are ready to engage in such conversations with their health care providers, ${ }^{6}$ some may indicate by their responses that they are not ready (e.g., "I do not plan to get sick," "I will wait until the time comes."). It is important to be sensitive to this and to recognize that such conversations are a process rather than a single event. If one senses a lack of readiness on the part of the patient, it may be useful to address barriers by asking whether there are things that he or she worries about when thinking about a loved one making decisions on his or her behalf, or whether there are reasons it is difficult to talk about such things with a physician or loved one. In addition, physicians can motivate patients to engage in advance care planning by appealing to benefits such as reducing the burden on substitute decision-makers and maintaining control of their future care. ${ }^{14}$

\section{Information exchange}

\section{How is a patient's life expectancy determined?}

Prognostic disclosure is an important component of end-of-life communication and decisionmaking, yet it occurs infrequently among patients in hospital with serious illnesses. ${ }^{15}$ There are several clinical prediction rules for death after admission to hospital (Appendix 1, available at www.cmaj.ca/lookup/suppl/doi:10 .1503/cmaj.121274/-/DC1; www.eprognosis 
.org). ${ }^{16-27}$ Although none of these tools is clearly superior, the system developed by Walter and colleagues ${ }^{16}$ has been externally validated ${ }^{28,29}$ has good predictive accuracy ( $C$ statistic 0.79 ) and incorporates easily obtainable information from multiple relevant domains (Figure 1). ${ }^{16}$ This tool provides an estimate of 1-year mortality for groups of patients similar to a physician's specific patient. It uses 6 risk factors to stratify medical patients 70 years of age and older according to 1-year mortality after admission to hospital. For example, in the validation cohort, patients in the highest risk group ( $>6$ points) have a 1-year mortality of $64 \%$ and a median survival of about 5.5 months. ${ }^{16}$ Such data can help inform broad statements about prognosis when patients ask how long they have left to live. In our experience, an example response to this question would be:

That is an important question, but one that is difficult to answer precisely. However, we can get a rough idea from other patients who have had similar conditions. What we can say is that for similar patients, lifeexpectancy tends to be measured in months, 3 to 6 for example, but it's important that you understand that there is no way that we can accurately predict how long any of us have to live. We can only give a rough guide, which may be helpful for us to plan and make certain decisions.

\begin{tabular}{|c|c|c|}
\hline \multicolumn{3}{|c|}{$\begin{array}{c}\text { Step } 1 \\
\text { Determine score using } \\
\text { validation cohort from } \\
\text { Walter and colleagues }{ }^{16}\end{array}$} \\
\hline \multicolumn{2}{|l|}{ Variable } & Score \\
\hline \multicolumn{2}{|c|}{$\begin{array}{l}\text { - Male sex } \\
\text { - Needs assistance with } \\
1-4 \text { ADLs at discharge } \\
\text { - Needs assistance with all } \\
\text { ADLs } \\
\text { - Congestive heart failure } \\
\text { - Cancer* } \\
\text { - Metastatic cancer } \\
\text { - Creatinine }>265 \mu \mathrm{mol} / \mathrm{L} \\
\text { - Serum albumin } 30-34 \mathrm{~g} / \mathrm{L} \\
\text { - Serum albumin }<30 \mathrm{~g} / \mathrm{L}\end{array}$} & $\begin{array}{l}1 \\
2 \\
5 \\
2 \\
3 \\
8 \\
2 \\
1 \\
2\end{array}$ \\
\hline \multicolumn{3}{|c|}{$\begin{array}{c}\text { Step } \mathbf{2} \\
\text { Use patient's score to } \\
\text { estimate 1-year mortality }\end{array}$} \\
\hline Total score & 1-year mo & ality, \% \\
\hline $0-1$ points & 4 & \\
\hline $2-3$ points & 19 & \\
\hline 4-6 points & 34 & \\
\hline$>6$ points & 64 & \\
\hline
\end{tabular}

Figure 1: Predicting 1-year mortality after admission to hospital. Note: ADL = activities of daily living. *Includes hematologic malignant disease.
Often, however, patients or families will not ask directly about the prognosis, and many physicians are uncomfortable starting this discussion or have difficulty handling the emotions that arise during these conversations. ${ }^{30,31}$ SPIKES (Setting up, perception, invitation, knowledge, emotions, strategy and summary; Box 3$)^{32,33}$ is a structured communication protocol reflecting the consensus of experts in breaking bad news and has shown to increase clinicians' confidence in dealing with difficult topics and the emotions they trigger. ${ }^{32,33}$

\section{What are the patient's values?}

Another important step in information exchange is to elicit or clarify a patient's values (i.e., what he or she considers important and what outcomes or states of health would be acceptable or unacceptable). Sudore and Fried ${ }^{14}$ suggest several ways in which health care providers can inquire about patients' values (see Box 4), and

Box 3: A process for sharing information about prognosis (SPIKES) *32,33 S: SETTING UP the interview

- Arrange for some privacy.

- Ask your patient who else to include in the interview (e.g., the substitute decision-maker).

- Consider involving a colleague (e.g., nurse, trainee or other appropriate member of the team who has developed a relationship with the patient).

- Sit down and make eye contact.

P: Assessing the patient's PERCEPTION

- Ask how the patient perceives his or her medical situation with questions such as "What have you been told about your medical situation so far?," 32 "Tell me what the last year has been like for you" or "What are your thoughts about the future?"

\section{I: Obtaining the patient's INVITATION}

- Determine what the patient wants to know (not everyone wants full information) with a question such as "Are you the sort of person who wants to hear all the details of your medical condition?"

K: Giving KNOWLEDGE and information

- Provide small chunks of information in simple language, checking periodically for understanding.

- Acknowledge uncertainty when disclosing prognosis (e.g., give a range instead of a single number).

\section{E: Addressing EMOTIONS with empathic responses}

- Identify emotions as they arise with statements such as "I can tell you weren't expecting to hear this," 32 "It sounds like you are feeling overwhelmed by this" or "It's natural that talking about this can be upsetting - for any of us. It's okay to take some time."

- Use exploratory questions or statements if there is silence, such as "Could you tell me more about what is worrying you?" ${ }^{32}$ or "I want to make sure that if you have questions or things you are worried about, we can help to address them."

\section{S: STRATEGY and SUMMARY}

- Summarize the major areas discussed.

- Make a plan for the next meeting.

*The suggested wording contained here can and should be modified by clinicians to suit their own communication style and to meet the individual needs and preferences of patients.

Statements without references are based on the authors' experiences. 
some advance care plans ask questions to enable patients to consider and document their values and preferences (see Appendix 2, available at www.cmaj.ca/lookup/suppl/doi:10.1503/cmaj.12 1274/-/DC1, or www.thecarenet.ca for an example of such a personal directive). Substitute decision-makers may experience negative emotional effects as a result of making choices on behalf of family members, particularly when they lack knowledge about the patient's values and preferences. ${ }^{34}$ Arming substitute decisionmakers with an understanding of the patient's values may enhance their preparedness to make in-the-moment health care decisions on behalf of their loved one, should the patient's condition deteriorate to the point that providing consent is no longer possible. ${ }^{14}$

\section{What are the risks and benefits of life-sustaining therapy?}

Cardiopulmonary resuscitation (CPR), as developed in the middle part of the 20th century, was a means to rescue patients from sudden death. ${ }^{35}$ However, sudden death is the least common endof-life trajectory (Figure 2), representing only about $5 \%$ of all deaths. ${ }^{36,37}$ Although CPR can be

\section{Box 4: Suggested statements and questions for conversations} about goals of care*14

\section{Determining a patient's values}

- "Have you previously had an experience with serious illness, or has someone close to you had an experience with serious illness or death?"14

- "If you were in this situation (again), what would you hope for? What would worry you most?"14

- "Did this situation make you think about states of being that would be so unacceptable to you that you would consider them to be worse than death?"14

\section{Establishing leeway in substitute decision-making}

- "What if, based on changes in your health, the doctors recommend something different from what you have told your loved one(s)?"14

- "Will you give your loved one(s) permission to work with your doctors to make the best decision possible for you, even if it may differ from what you said you wanted in the past?"14

- "Are there certain decisions about your health that you would never want your loved one(s) to change under any circumstances?" 14

\section{Aligning language with the patient's preferred mode of decision-} making

- Shared decision-making: "Based on what you've said, it seems to me that the most reasonable course of action is ..." (i.e., avoid asking "What would you like us to do?" to avoid placing the burden of the decision solely on the patient).

- Active decision-maker: "It is up to you to decide, but many people in your circumstances would consider it acceptable to ..." (i.e., legitimize the difficult option, but leave the patient as the final decision-maker).

- Passive decision-maker: "I recommend that we do the following ..." (i.e., declare the plan).

*The suggested wording contained here can and should be modified by clinicians to suit their own communication style and to meet the individual needs and preferences of patients.

Statements without references are based on the authors' experiences. very effective for sudden cardiac events, its effectiveness in preventing death and disability for patients who have a terminal illness, progressive organ failure or chronic frailty is markedly diminished. Overall in-hospital survival after CPR is about $15 \%-20 \%$ ( 1 in $5-7$ patients); for patients without a shockable rhythm (i.e., patients with rhythms other than ventricular fibrillation or pulseless ventricular tachycardia, such as asystole or pulseless electrical activity), survival decreases to about $10 \%$ ( 1 in 10 patients); among patients who are the most sick and in the intensive care unit, survival is between $1 \%$ and $5 \%$ ( 1 in 100 patients to 1 in 20 patients). ${ }^{38-44}$ Moreover, of the few patients who survive inhospital CPR, most will have substantially diminished function. Many of these patients (30\%-70\%, depending on the population) will have substantial disability and be dependent on others for daily support, or they will be discharged to hospice care, a nursing home or another hospital. ${ }^{38,39,44}$ Although undergoing CPR is now sometimes seen as the "default" position for all patients, for most final end-of-life trajectories, its indiscriminate application may lead to a prolonged period of diminished quality of life, with no ability to reverse the underlying cause. Decision aids may be useful tools to increase patients' and family members' understanding of the risks and benefits of CPR (see www .thecarenet.ca/docs/CPRDecision_Aid_formatted _20101110.pdf for an example of such an aid). ${ }^{45-47}$

\section{Reaching a decision}

\section{What process issues should be considered when deciding the goals of care?}

Studies have shown that a substitute decisionmaker's perception of what a patient would want may not always agree with the patient's actual preferences. ${ }^{48-51}$ Furthermore, discussions between patients and their substitute decisionmakers about advance care planning are associated with higher levels of agreement. ${ }^{48-51}$ Therefore, clinicians should ask patients to invite substitute decision-makers to be involved in these discussions so that they are accurately informed about patients' values and preferences for care at the end of life. Because substitute decisionmakers may be required to make in-the-moment decisions under conditions of uncertainty, they should be involved in goals-of-care discussions so that patients can establish leeway in substitute decision-making. For example, if a patient is in a state of health that he or she has declared unacceptable, the substitute decision-maker may be given no leeway; however, under conditions of uncertainty, the substitute decision-maker may 
be given leeway to make decisions guided by the patient's previously expressed values and preferences (Box 4)..$^{14}$

Ensuring open disclosure of prognostic information and the risks and benefits of treatment is important during information exchange. At the point when decisions are being made, however, clinicians should recognize that although most patients will prefer a process of shared decisionmaking, ${ }^{52,53}$ individual patients will have their own preferred mode of decision-making that lies on a spectrum ranging from a purely "informed consumer" model (patient decides) to a "paternalistic" model (health care team decides). Clinicians should assess the patient's preferred mode of decision-making, involve family members whenever possible (and to the extent it is desired by the patient) and be prepared to have some degree of flexibility in meeting the decision-making needs of individual patients and their families (Box 4). ${ }^{14}$

Although goals-of-care discussions will nearly always improve common understanding, they do not guarantee that conflict over the most appropriate care plan will not arise among patients, families and the health care team, between patients and their family members or within a family. When patients are capable of directing their own care,,$^{54}$ they need to be invited to take part in decision-making about their care. When patients are incapable of decision-making or defer the responsibility to others, substitute decision-makers have a responsibility to act in accordance with patients' stated or understood beliefs, values and wishes. This role can be difficult for grieving substitute decision-makers who may carry with them the notion of unfinished communication or relationship-related guilt.

It is often difficult for substitute decisionmakers to separate "doing what the patient would want me to do" from "doing what I want for the patient." Making this distinction for substitute decision-makers when you sense conflict is important to reassure them that even though they may desire something different (e.g., all attempts possible to prolong life for their loved one), the physician's responsibility is to act as the patient would direct, within the boundaries of what is medically reasonable. Many jurisdictions and hospitals have helpful pathways for encouraging a best practice. ${ }^{55-57}$ Although Canadian

\section{A}

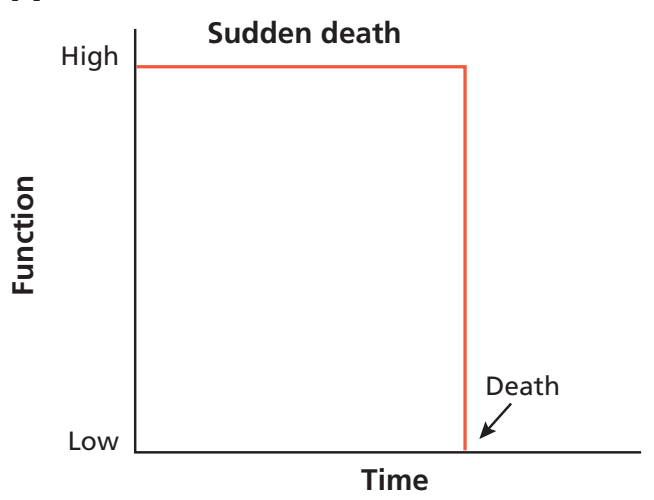

C

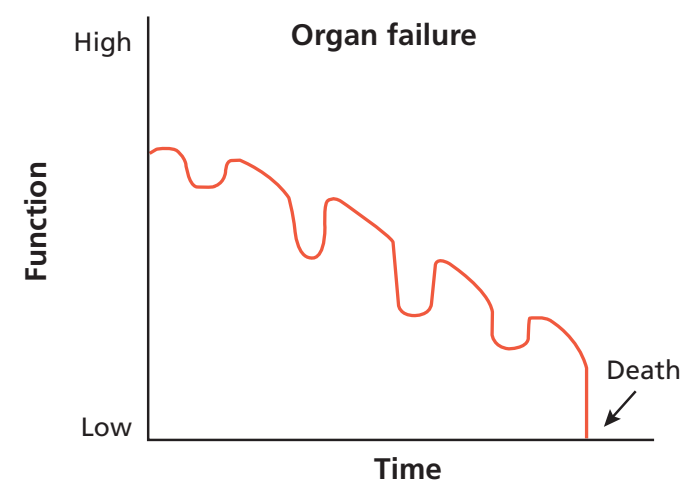

B

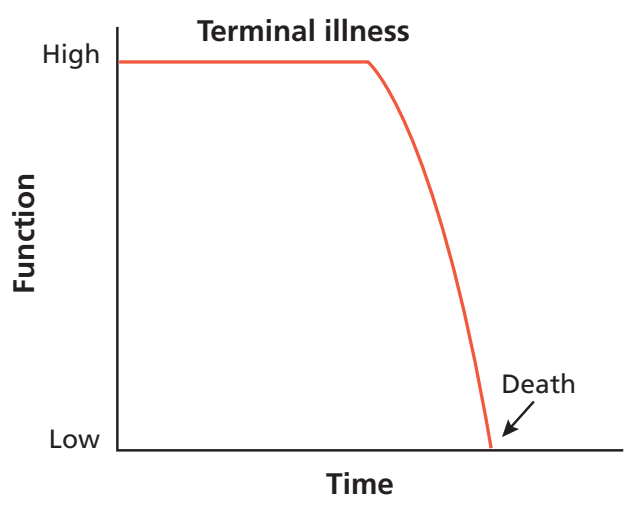

D

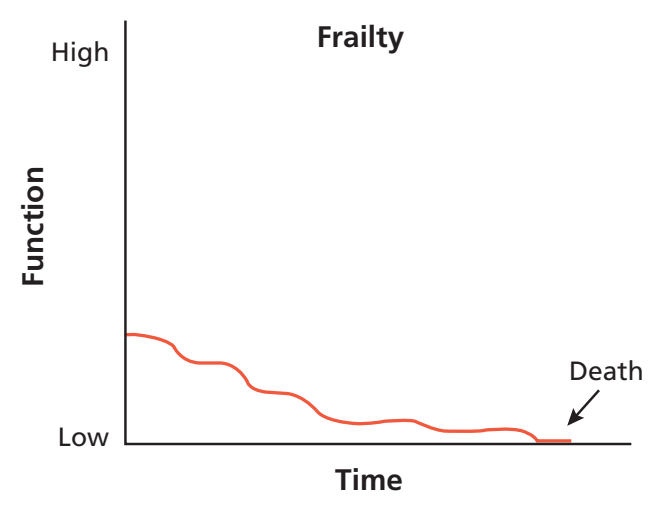

Figure 2: End-of-life trajectories. Reproduced with permission from Lunney JR, Lynn J, Hogan C. Profiles of older medicare decedents. J Am Geriatr Soc 2002;50:1108-12. ${ }^{36}$ 
courts have generally not mandated that health care teams provide therapy that is counter to what they believe is medically warranted and appropriate, the legal and quasilegal processes for resolving such conflict outside the hospital setting require clarification at federal and provincial/territorial levels.

\section{Box 5: Applying the results of this review in practice}

You are caring for a 79-year-old man on your hospital ward, a widower for several years, who was admitted 2 days ago with an exacerbation of chronic obstructive pulmonary disease. The patient has several other chronic illnesses, including congestive heart failure, diabetes mellitus, chronic kidney disease (creatinine 280 [normal 50-98] $\mu \mathrm{mol} / \mathrm{L}$ ) and mild cognitive impairment. He is finding it increasingly difficult to manage at home alone. Although his acute symptoms have abated, he is still short of breath, slow to move and not yet ready for discharge. You notice that there is no documentation of code status and that his wishes for end-of-life are unknown to you.

You ask yourself "Would I be surprised if this patient died in the next year?" Having answered "No" to this question, you obtain a more precise estimate of 1-year mortality for this patient using the clinical prediction rule of Walter and colleagues ${ }^{16}$ (male sex, 1 point; inability to perform activities of daily living, 2 points; congestive heart failure, 2 points; creatinine $>265 \mu \mathrm{mol} / \mathrm{L}, 2$ points), estimating a 1-year risk of death for this patient of $64 \%$ (95\% confidence interval $58 \%-70 \%)$. The patient tells you that he does not have an advance directive or living will. When asked who he would like present for discussions about his future care, he tells you he would like his daughter to be there, and you arrange to meet with them together the next day.

During the conversation, you elicit that the past year has been difficult for the patient because he is becoming more frail and increasingly housebound, and has had increasing difficulty performing his activities of daily living and becoming increasingly housebound. You explain the range of prognoses for patients similar to him, determine what is important to him (he tells you that he does not want to be kept alive in a state where he is fully dependent on others for care) and document in the medical record his expressed wishes not to receive life-sustaining interventions

(cardiopulmonary resuscitation and mechanical ventilation) should his condition deteriorate acutely.

\section{Box 6: Additional resources}

- "Speak up: start the conversation about end-of-life care" is a public awareness campaign led by the Canadian Hospice Palliative Care Association and its partners. The website contains links to resources and advance care planning tools for patients and family members (www .advancecareplanning.ca/).

- ePrognosis is a website containing online calculators to estimate prognosis for older adults in a variety of settings (community, hospital, long-term care facility) over several time frames ( $<2 \mathrm{yr}$ to $>3 \mathrm{yr}$ ) (www.eprognosis.org).

- CARENET (Canadian Researchers at the End of Life Network) is a group of health care professionals from across Canada who collaborate to improve palliative and end-of-life care. The website contains links to resources for patients, family members, health care professionals and researchers, including ongoing quality-improvement initiatives (www.thecarenet.ca).

- The Canadian Hospice Palliative Care Association (CHPCA) is the national voice for hospice palliative care in Canada. Advancing and advocating for quality end-of-life and hospice palliative care in Canada, its work includes public policy, public education and awareness (www.chpca.net)

\section{How should these decisions be documented?}

Decisions about goals of care should be clearly documented in the medical record and include the values that have informed these choices by using examples and the patient's own words. Such a record maximizes the likelihood that a patient's previously expressed wishes will be successfully translated into actual care received. Many jurisdictions are adopting standardized forms or order sets (e.g., Goals of Care Designations in the Calgary Zone of Alberta Health Services; Medical Orders for Scope of Treatment in the Fraser Health Authority, British Columbia) $)^{58.59}$ to provide clear documentation of the types of life-sustaining treatment wanted or not wanted by a patient. Moreover, there are ongoing initiatives to make these documents highly visible and transportable across care settings (e.g., physically portable folders, regional electronic repositories or registries of care plans, embedding the plans into a common electronic medical record) to facilitate timely communication about a patient's wishes for care.

\section{Unanswered questions}

Evidence regarding tools or strategies to help patients and families work through the end-of-life decision-making process is emerging. Three randomized controlled trials have found that videobased decision aids, when delivered to community-dwelling older adults or to outpatients with cancer, can reduce uncertainty regarding decision-making and help clarify patients' preferred goals for future care when compared with verbal description alone. ${ }^{45,46,60} \mathrm{~A}$ recent, single-centre randomized controlled trial enrolled older adult patients in hospital showed that, compared with usual care, an advance care planning intervention delivered by a trained, nonphysician facilitator resulted in greater patient and family satisfaction with care and a greater proportion of patients for whom end-of-life wishes were known and respected at the time of death. ${ }^{2}$ Although these developments are promising, it remains unknown whether video decision aids or other tools, when implemented in clinical practice in an acute care setting, can improve outcomes that are important to patients in hospital with serious illnesses and their families, such as quality of life, satisfaction with end-of-life care, treatment that is concordant with their previously expressed wishes, and levels of anxiety and depression felt by bereaved relatives. In addition, it is uncertain whether more sustainable models of advance care planning that do not rely on training nonphysician facilitators can be successfully developed. 
The optimal time to begin discussing goals of care during a hospital stay is not known. Broaching these discussions in a busy emergency department when the patient's condition is still being stabilized may not be the ideal setting, although it may be required if there are signs of an impending deterioration in the patient's condition. Indeed, it may not be feasible or desirable to comprehensively address all of the items covered in this conversation guide during a single encounter. Clinicians should exercise judgment and flexibility in engaging patients and family members in these discussions, recognizing that determining goals of care is a process. For patients who have existing advance directives, this process may be straightforward; for others who may be less prepared, the discussion may best unfold in a phased approach, with initial introduction and probing of this issue early during the stay in hospital and more detailed followup later on.

\section{Conclusion}

We hope that the suggestions provided here will enable greater discussion of end-of-life care in the acute care hospital setting (Boxes $5^{16}$ and 6). Engagement in regular audits of end-of-life communication and decision-making may help drive local quality improvement in the hospital setting. Outside of the hospital setting, we suggest that parallel efforts be made to increase public awareness and education about the limitations of lifesustaining technologies and the importance of advance care planning. ${ }^{61,62}$

\section{References}

1. Wright AA, Zhang B, Ray A, et al. Associations between endof-life discussions, patient mental health, medical care near death, and caregiver bereavement adjustment. JAMA 2008;300: 1665-73.

2. Detering KM, Hancock AD, Reade MC, et al. The impact of advance care planning on end of life care in elderly patients: randomised controlled trial. BMJ 2010;340:c1345.

3. Zhang B, Wright AA, Huskamp HA, et al. Health care costs in the last week of life: associations with end-of-life conversations. Arch Intern Med 2009;169:480-8.

4. Heyland DK, Dodek P, Rocker G, et al. What matters most in end-of-life care: perceptions of seriously ill patients and their family members. CMAJ 2006;174:627-33.

5. Heyland DK, Cook DJ, Rocker GM, et al. Defining priorities for improving end-of-life care in Canada. CMAJ 2010;182:E747-52.

6. Heyland DK, Barwich D, Pichora D, et al. Failure to engage hospitalized elderly patients and their families in advance care planning. JAMA Intern Med. 2013;173:778-87.

7. Heyland DK, Tranmer J, Feldman-Stewart D. End-of-life decision making in the seriously ill hospitalized patient: an organizing framework and results of a preliminary study. J Palliat Care 2000;16(Suppl):S31-9.

8. Moss AH, Lunney JR, Culp S, et al. Prognostic significance of the "surprise" question in cancer patients. J Palliat Med 2010; 13:837-40.

9. Moss AH, Ganjoo J, Sharma S, et al. Utility of the "surprise" question to identify dialysis patients with high mortality. Clin J Am Soc Nephrol 2008;3:1379-84.

10. Della Penna R. Asking the right question. J Palliat Med 2001;4: 245-8.
11. Pattison M, Romer AL. Improving care through the end of life: launching a primary care clinic-based program. J Palliat Med 2001;4:249-54.

12. Heyland DK, Groll D, Rocker G, et al. End-of-life care in acute care hospitals in Canada: A quality finish? J Palliat Care 2005; 21:142-50.

13. Christakis NA, Lamont EB. Extent and determinants of error in doctors' prognoses in terminally ill patients: prospective cohort study. BMJ 2000;320:469-72.

14. Sudore RL, Fried TR. Redefining the "planning" in advance care planning: preparing for end-of-life decision making. Ann Intern Med 2010;153:256-61.

15. Heyland DK, Allan DE, Rocker G, et al. Discussing prognosis with patients and their families near the end of life: impact on satisfaction with end-of-life care. Open Med 2009;3:e101-10.

16. Walter LC, Brand RJ, Counsell SR, et al. Development and validation of a prognostic index for 1-year mortality in older adults after hospitalization. JAMA 2001;285:2987-94.

17. Dramé M, Novella JL, Lang PO, et al. Derivation and validation of a mortality-risk index from a cohort of frail elderly patients hospitalised in medical wards via emergencies: the SAFES study. Eur J Epidemiol 2008;23:783-91.

18. Drame M, Jovenin N, Novella JL, et al. Predicting early mortality among elderly patients hospitalised in medical wards via emergency department: the SAFES cohort study. J Nutr Health Aging 2008; 12:599-604.

19. Fischer SM, Gozansky WS, Sauaia A, et al. A practical tool to identify patients who may benefit from a palliative approach: the CARING criteria. J Pain Symptom Manage 2006;31:285-92.

20. Inouye SK, Peduzzi PN, Robison JT, et al. Importance of functional measures in predicting mortality among older hospitalized patients. JAMA 1998;279:1187-93.

21. Inouye SK, Bogardus ST Jr, Vitagliano G, et al. Burden of illness score for elderly persons: risk adjustment incorporating the cumulative impact of diseases, physiologic abnormalities, and functional impairments. Med Care 2003;41:70-83.

22. Knaus WA, Harrell FE Jr, Lynn J, et al. The SUPPORT prognostic model. Objective estimates of survival for seriously ill hospitalized adults. Study to understand prognoses and preferences for outcomes and risks of treatments. Ann Intern Med 1995;122: 191-203.

23. Levine SK, Sachs GA, Jin L, et al. A prognostic model for 1year mortality in older adults after hospital discharge. Am J Med 2007; 120:455-60

24. Teno JM, Harrell FE Jr, Knaus W, et al. Prediction of survival for older hospitalized patients: the HELP survival model. Hospitalized Elderly Longitudinal Project. J Am Geriatr Soc 2000;48:S16-24.

25. Yourman LC, Lee SJ, Schonberg MA, et al. Prognostic indices for older adults: a systematic review. JAMA 2012;307:182-92.

26. Di Bari M, Balzi D, Roberts AT, et al. Prognostic stratification of older persons based on simple administrative data: development and validation of the "silver code," to be used in emergency department triage. J Gerontol A Biol Sci Med Sci 2010;65:159-64.

27. Pilotto A, Ferrucci L, Franceschi M, et al. Development and validation of a multidimensional prognostic index for one-year mortality from comprehensive geriatric assessment in hospitalized older patients. Rejuvenation Res 2008;11:151-61.

28. Pérez Bocanegra MC, Villegas E, Guallar A, et al. Usefulness of a new index for mortality after hospitalization in adults older than 70 years [article in Spanish]. Med Clin (Barc) 2006;127:492-3.

29. Rozzini R, Sabatini T, Trabucchi M. Prediction of 6-month mortality among older hospitalized adults. JAMA 2001;286:1315-6.

30. Maguire P, Pitceathly C. Key communication skills and how to acquire them. BMJ 2002;325:697-700.

31. Baile WF, Kudelka AP, Beale EA, et al. Communication skills training in oncology. Description and preliminary outcomes of workshops on breaking bad news and managing patient reactions to illness. Cancer 1999;86:887-97.

32. Baile WF, Buckman R, Lenzi R, et al. SPIKES - a six-step protocol for delivering bad news: application to the patient with cancer. Oncologist 2000;5:302-11.

33. Garg A, Buckman R, Kason Y. Teaching medical students how to break bad news. CMAJ 1997;156:1159-64

34. Wendler D, Rid A. Systematic review: the effect on surrogates of making treatment decisions for others. Ann Intern Med 2011; 154:336-46.

35. Zoll PM, Linenthal AJ, Gibson W, et al. Termination of ventricular fibrillation in man by externally applied electric countershock. N Engl J Med 1956;254:727-32.

36. Lunney JR, Lynn J, Hogan C. Profiles of older Medicare decedents. J Am Geriatr Soc 2002;50:1108-12.

37. Canadian Institute for Health Information. Health care use at the end of life in western Canada. Ottawa (ON): The Institute; 2007.

38. Ehlenbach WJ, Barnato AE, Curtis JR, et al. Epidemiologic 
study of in-hospital cardiopulmonary resuscitation in the elderly. N Engl J Med 2009;361:22-31.

39. Tian J, Kaufman DA, Zarich S, et al. Outcomes of critically ill patients who received cardiopulmonary resuscitation. Am J Respir Crit Care Med 2010;182:501-6.

40. Brindley PG, Markland DM, Mayers I, et al. Predictors of survival following in-hospital adult cardiopulmonary resuscitation. CMAJ 2002;167:343-8.

41. Peberdy MA, Kaye W, Ornato JP, et al. Cardiopulmonary resuscitation of adults in the hospital: a report of 14720 cardiac arrests from the National Registry of Cardiopulmonary Resuscitation. Resuscitation 2003;58:297-308.

42. Ebell MH, Becker LA, Barry HC, et al. Survival after in-hospital cardiopulmonary resuscitation. A meta-analysis. J Gen Intern Med 1998;13:805-16.

43. Peberdy MA, Ornato JP, Larkin GL, et al. Survival from in-hospital cardiac arrest during nights and weekends. JAMA 2008;299:785-92.

44. Girotra S, Nallamothu BK, Spertus JA, et al. Trends in survival after in-hospital cardiac arrest. N Engl J Med 2012;367:1912-20.

45. Volandes AE, Paasche-Orlow MK, Barry MJ, et al. Video decision support tool for advance care planning in dementia: randomised controlled trial. BMJ 2009;338:b2159.

46. El-Jawahri A, Podgurski LM, Eichler AF, et al. Use of video to facilitate end-of-life discussions with patients with cancer: a randomized controlled trial. J Clin Oncol 2010;28:305-10.

47. Volandes AE, Levin TT, Slovin S, et al. Augmenting advance care planning in poor prognosis cancer with a video decision aid: a preintervention-postintervention study. Cancer 2012;118:4331-8.

48. Shalowitz DI, Garrett-Mayer E, Wendler D. The accuracy of surrogate decision makers: a systematic review. Arch Intern Med 2006;166:493-7.

49. Sudore RL, Schickedanz AD, Landefeld CS, et al. Engagement in multiple steps of the advance care planning process: a descriptive study of diverse older adults. J Am Geriatr Soc 2008;56:1006-13.

50. Schwartz CE, Wheeler HB, Hammes B, et al. Early intervention in planning end-of-life care with ambulatory geriatric patients: results of a pilot trial. Arch Intern Med 2002;162:1611-8.

51. Barrio-Cantalejo IM, Molina-Ruiz A, Simon-Lorda P, et al. Advance directives and proxies' predictions about patients' treatment preferences. Nurs Ethics 2009;16:93-109.

52. Heyland DK, Frank C, Groll D, et al. Understanding cardiopulmonary resuscitation decision making: perspectives of seriously ill hospitalized patients and family members. Chest 2006;130:419-28.

53. Heyland DK, Cook DJ, Rocker GM, et al. Decision-making in the ICU: perspectives of the substitute decision-maker. Intensive Care Med 2003;29:75-82.

54. Etchells E, Sharpe G, Elliott C, et al. Bioethics for clinicians: 3 . Capacity. CMAJ 1996;155:657-61.

55. College of Physicians and Surgeons of Ontario. Decisionmaking for the end of life. Toronto (ON): The College; 2006.
Available: www.cpso.on.ca/policies/policies/default.aspx ?ID=1582. (accessed 2012 June 11)

56. College of Physicians and Surgeons of Manitoba. Withholding and withdrawing life-sustaining treatment. Winnipeg (MB): The College; 2007. Available: http://cpsm.mb.ca/cjj39alckF30a/wp-content /uploads/st1602.pdf. (accessed 2012 June 11).

57. Sibbald RW, Chidwick P, Handelman M, et al. Checklist to meet ethical and legal obligations to critically ill patients at the end of life. Healthc $Q 2011 ; 14: 60-6$.

58. Advance care planning: goals of care designation. Edmonton (AB): Alberta Health Services. Available: www.albertahealth services.ca/ps-1023351-acp-policy-append-a.pdf. (accessed 2012 July 25).

59. Medical Orders for Scope of Treatment (MOST) and Advance Care Planning (ACP). Surrey (BC): Fraser Health; 2012. Available: http://physicians.fraserhealth.ca/media/Medical\%200rdersfor $\% 20$ Scope $\% 20$ of\%20Treatment\%20(MOST)\%20and\%20Advance $\% 20$ Care\%20Planning\%20(ACP).pdf (accessed 2013 Feb. 6).

60. Volandes AE, Ferguson LA, Davis AD, et al. Assessing end-oflife preferences for advanced dementia in rural patients using an educational video: a randomized controlled trial. J Palliat Med 2011;14:169-77.

61. Drawing the line on end-of-life care [editorial]. The Globe and Mail [Toronto (ON)] 2011 Nov. 25. Available: www.theglobe andmail.com/life/health-and-fitness/drawing-the-line-on-end-of-life -care/article534584/ (accessed 2012 May 7).

62. Priest L. Visit Sunnybrook's critical care unit [video]. The Globe and Mail [Toronto (ON)] 2011 Nov. 25. Available: www.theglobe andmail.com/life/health-and-fitness/video-visit-sunnybrooks-critical -care-unit/article609406/ (accessed 2012 May 7).

Affiliations: Department of Medicine and Department of Clinical Epidemiology and Biostatistics (You), McMaster University, Hamilton, Ont.; Department of Medicine (Fowler), University of Toronto, Toronto, Ont.; Department of Medicine (Heyland), Queen's University, Kingston, Ont.

Contributors: Each of the authors made substantial contributions to the conception and drafting of the article, revised the manuscript critically for important intellectual content and approved of the final version submitted for publication.

Acknowledgements: The authors thank Neera Bhatnagar for conducting the literature search to support this work, and Dr. John MacDonald and Dr. Michael Hartwick for their helpful comments on an earlier version of the manuscript. Dr. John You is supported by a Hamilton Health Sciences Research Early Career Award. 